\title{
On the association of terrestrial gamma-ray bursts with lightning and implications for sprites
}

\author{
Umran S. Inan and Steven C. Reising \\ STAR Laboratory, Stanford University, Stanford, California \\ Gerald J. Fishman and John M. Horack \\ NASA Marshall Space Flight Center, Huntsville, Alabama
}

East-West $(\mathrm{E} / \mathrm{W})]$ antennas allow the reconstruction of the arrival azimuth direction of the signals with $180^{\circ}$ ambiguity, using wideband ELF/VLF direction finding [Burgess, 1993].

Sferics are impulsive electromagnetic signals launched into the earth-ionosphere waveguide by lightning discharges [Budden, 1961; pp. 5, 69], which can propagate with little attenuation, typically $\sim 1 \mathrm{~dB} / \mathrm{Mm}$ at large distances from the source [e.g., Davies, 1990; p. 389], and are thus observable at large distances $(>12 \mathrm{Mm})$ from the source.

The BATSE detector on the CGRO is described elsewhere ([Fishman et al., 1994] and references therein). The instrument is triggered by the detection of gamma-ray bursts of intensity above a preset threshold, and accumulates high temporal resolution data for about 10 minutes, during which time it cannot re-trigger [Fishman et al., 1994]. During the subsequent read-out time ( $90 \mathrm{~min})$ the instrument can only re-trigger on a more intense event. The source direction of the bursts can be estimated (rather imprecisely due to the penetrating nature of the photons) by comparing the responses of the eight BATSE detectors.

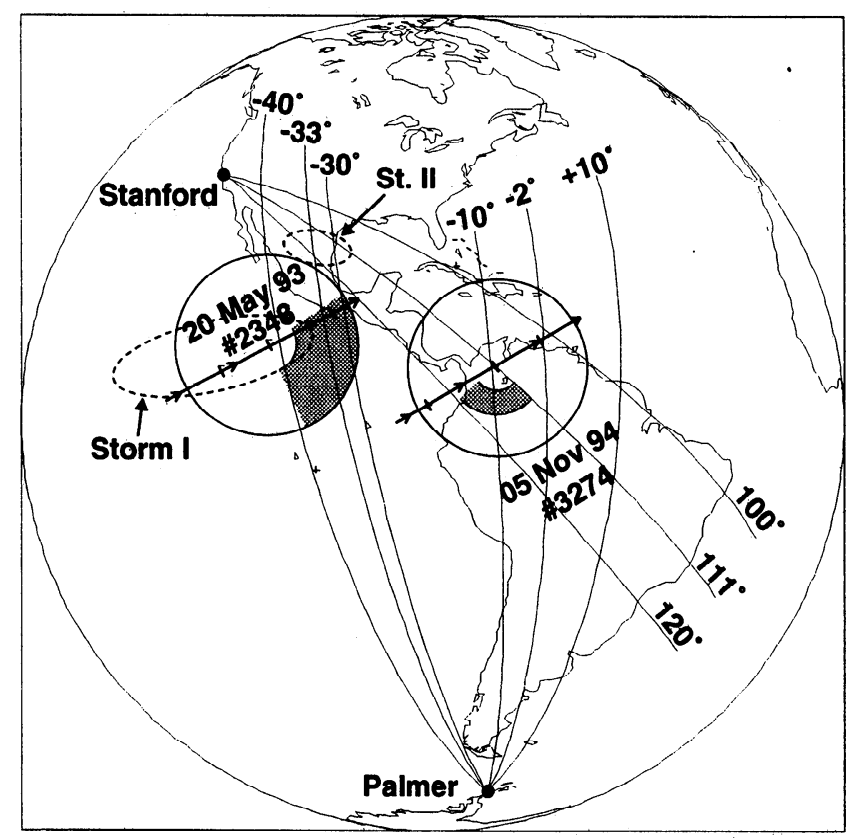

Figure 1. The orbital track and the horizon circle of the CGRO during Bursts 2348 and 3274. The shaded regions are the inferred (based on BATSE data) source locations. The dotted ovals show the locations of two separate storms on 20 May 93 (Figure 3). The lines originating at Palmer (and at Stanford for 3274) are the arrival azimuth bearings, with the central lines indicating the azimuth of the peak activity (Figure 3 ). 


\section{Observations}

Of the $\sim 50$ terrestrial gamma-ray bursts observed on the CGRO, Palmer ELF/VLF data were available for four bursts identified as $1915,2340,2348$, and 3274 . In two cases (1915 and 2340), data were inconclusive as to the detection of thunderstorm activity because the paths from the CGRO footprints to Palmer cross the polar cap, with consequent high losses due to the ice-sheet and intense electron precipitation in the auroral regions [e.g., Westerlund and Reder, 1973]. The sferics data for the two bursts 2348 and 3274 (Figure 1), with closer source locations $(\sim 8700 \mathrm{~km}$ and $\sim 7700 \mathrm{~km})$, are presented below as cases A and B.

\section{Case A: Gamma-Ray Burst 2348}

Dynamic spectra of sferics observed at Palmer during a 2-sec period centered at the time of Burst 2348 are shown in Figure 2, indicating many sferics arriving from the northwest, consistent with the azimuth bearing from Palmer of the CGRO (see Figure 1). The onset of sferic AE (Figure 5) was observed at 0202:17.680土.001 UT, while Burst 2348 was recorded by BATSE at 0202:17.655 UT. Assuming the sferic source to be at point $\mathrm{P}$ in Figure 4, a propagation delay to Palmer of $29.2 \mathrm{~ms}$ places the causative lightning of sferic AE to be 0202:17.6508 \pm .001 UT. Assuming Burst 2348 to be generated at $50 \mathrm{~km}$ altitude, the $2.8 \mathrm{~ms}$ speed-of-light delay from point $\mathrm{P}$ to $\mathrm{CGRO}$ (at $500-\mathrm{km}$ altitude) indicates that the peak of Burst 2348 occurred $1.4 \pm 1 \mathrm{~ms}$ after the onset of sferic AE. Considering that sferics of intensity greater than or equal to that of $\mathrm{AE}$ occurred at a rate of $\sim 4 \mathrm{~min}^{-1}$ during this period (see Table 1 and the bottom panel of Figure 3),
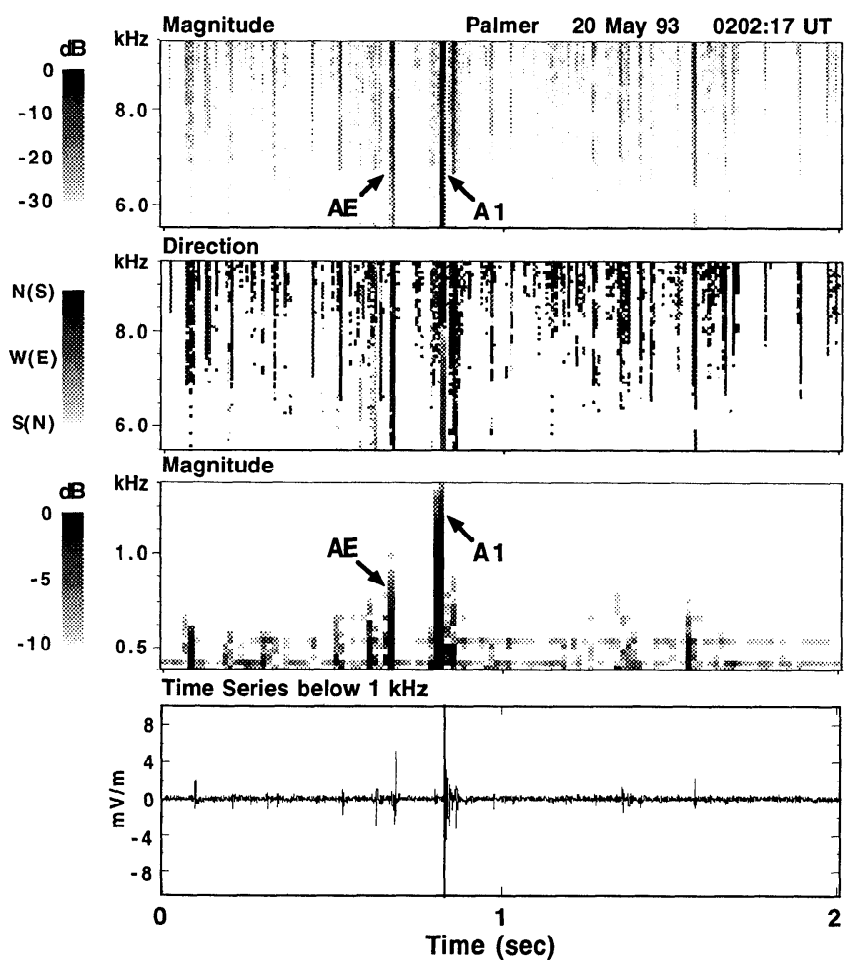

Figure 2. The first and third panels show frequencytime spectrograms, of VLF and ELF bands respectively, of sferics observed at Palmer. Two sferics marked AE and $\mathrm{A} 1$ are discussed in the text. $\mathrm{AE}$ is the 'event' sferic, launched by the lightning discharge which led to Burst 2348. The second panel indicates the arrival azimuth of the sferics. The bottom panel shows the time-series waveform of the lowpass filtered $(<1 \mathrm{kHz})$ data. the probability of chance occurrence of such a sferic in any given $1 \mathrm{~ms}$ interval is $10^{-5}$, suggesting that Burst 2348 was generated by the energy released in the lightning discharge that launched sferic AE.

The occurrence peak in Figure 3 between $-40^{\circ}$ and $-30^{\circ}$ (cf. Figure 1) shows the extent of thunderstorm activity near the footprint of CGRO. Bascd on the GOES-7 infrarcd image shown in Figure 3a of Fishman et al.[1994], this arrival azimuth range is consistent with the coldest cloud tops measured above Storm I in the CGRO region as well as Storm II over the western shore of the Gulf of Mexico, both of which might have produced sferics.

The magnitude axis in Figure 3 represents the timeaverage intensity of sferics over a 10 -ms duration, starting 1 $\mathrm{ms}$ before the onset (see Figure 5). Characteristics of the 10 strongest sferics between 0150 and $0220 \mathrm{UT}$ and the three sferics nearest the gamma-ray burst time are in Table 1. Nine of these sferics (A1, A3, A4, A5, A7, A9, AE-2, AE-1 and $\mathrm{AE}$ ) have azimuths in the range $-39^{\circ}$ to $-36^{\circ}$, placing them clearly in the CGRO storm (I) instead of the Gulf storm (II). Sferics A1 and AE are marked in Figure 2. A1, which occurs $145 \mathrm{~ms}$ after Burst 2348, is by far the strongest sferic measured during this $30-\mathrm{min}$ period, while $\mathrm{AE}$ ranks between 80th and 85th (see Figure 3, bottom panel).

Since the sferic due to a CG discharge is an electromagnetic pulse radiated by the return stroke current, the onset of its waveform at a distant receiver either initially increascs or decreases depending on the polarity of the return stroke current. With the system polarity unambiguously resolved via comparison with National Lightning Detection Network (NLDN) data, most of the sferics in Table 1 were determined to be produced by positive discharges; this determi-
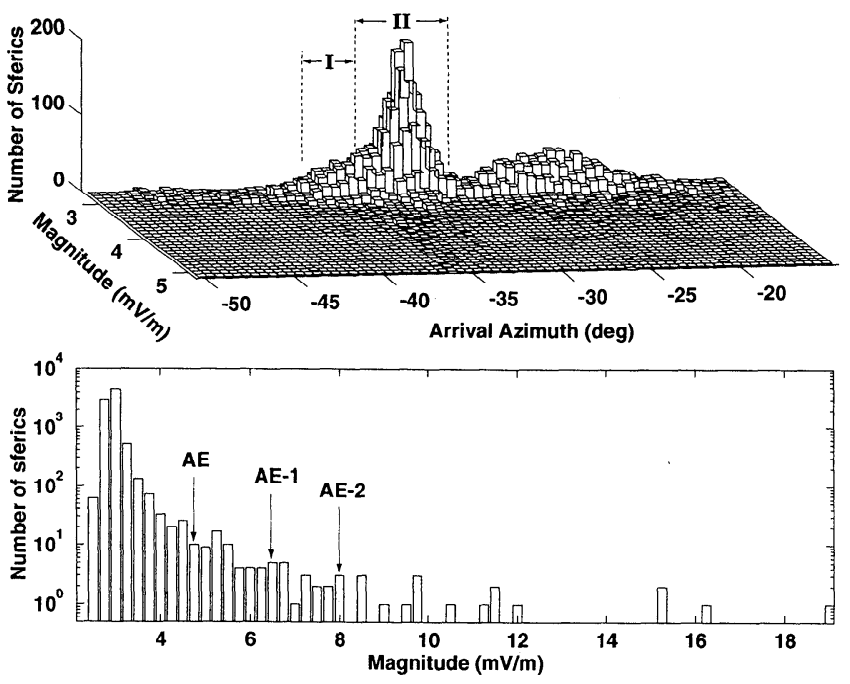

Figure 3. Intensity and arrival azimuth distribution of sferics observed at Palmer in the arrival azimuth range from $-50^{\circ}$ to $-15^{\circ}$ during the 30 -minute period 0150 0220 UT on 20 May 1993. Arrival azimuth is in degrees clockwise from north, with west denoted as $-90^{\circ}$ and east as $+90^{\circ}$. The sferics were detected (as having peak intensity above a set threshold) and their arrival bearings were measured on the basis of their energy in the 5.5 to $9.5 \mathrm{kHz}$ range. The sferic magnitudes are the time-average intensities as defined in the text. The dashed lines denote the azimuth ranges of the coldest cloud tops of the storm in the CGRO region (I) and of the Gulf coast storm (II) (dotted ovals in Figures 1 and 4), derived from the GOES-7 infrared image for the same time period (shown in Figure 3a of Fishman et al.[1994]). The bottom panel shows a magnitude histogram. 
Table 1. Characteristics of Selected Sferics

\begin{tabular}{ccccc}
\hline Label & $\begin{array}{c}\text { Time } \\
(\mathrm{UT})\end{array}$ & $\begin{array}{c}\text { Magnitude } \\
(\mathrm{mV} / \mathrm{m})\end{array}$ & $\begin{array}{l}\text { Azimuth } \\
(\mathrm{deg})\end{array}$ & Polarity \\
\hline A1 & $0202: 17.825$ & 26.78 & -35.7 & positive \\
A2 & $0219: 51.110$ & 22.32 & -14.8 & positive \\
A3 & $0201: 05.366$ & 19.26 & -36 & positive \\
A4 & $0211: 41.708$ & 15.26 & -38.8 & positive \\
A5 & $0152: 10.865$ & 15.10 & -35.8 & positive \\
A6 & $0159: 59.365$ & 13.51 & -54.9 & positive \\
A7 & $0158: 53.965$ & 12.97 & -35.8 & negative \\
A8 & $0219: 51.383$ & 11.11 & -16.3 & positive \\
A9 & $0200: 54.702$ & 11.07 & -35.8 & positive \\
A10 & $0217: 21.283$ & 11.07 & -28.3 & positive \\
AE-2 & $0201: 43.779$ & 7.97 & -35.8 & positive \\
AE-1 & $0201: 46.973$ & 6.44 & -39.7 & uncertain \\
AE & $0202: 17.680$ & 4.72 & -35.7 & positive \\
\hline
\end{tabular}

nation presumes CG lightning discharges, consistent with large continuing currents [Brook et al., 1982].

Figure 4 shows the passage of the CGRO over this storm. Sferics $\mathrm{A} 1$ and $\mathrm{A} 3$ are the two sferics of the top ten ( $\mathrm{Ta}$ ble 1) nearest in time to Burst 2348, whereas AE-2 and $\mathrm{AE}-1$ are the only two of greater intensity than the event sferic (AE) which occur between A3 and AE. The arrival bearings in Figures 1,2 and 4 show consistency with the inferred source location of Burst 2348 (i.e., the shaded region). As the CGRO approached the 'source' region, sferic A3 occurred at 0201:05.366 UT within $\pm 2^{\circ}$ of the corresponding azimuth line in Figure 4. Although this sferic was very intense, no gamma rays were detected on CGRO, possibly because the source was beyond the horizon circle. It is also possible that the particular lightning flash that led to A3 did not produce a gamma-ray burst, or that the gamma rays were beamed. The same circumstance was probably in effect for the weaker sferics AE-2 and AE-1. Once BATSE was triggered by Burst 2348 associated with sferic AE, it

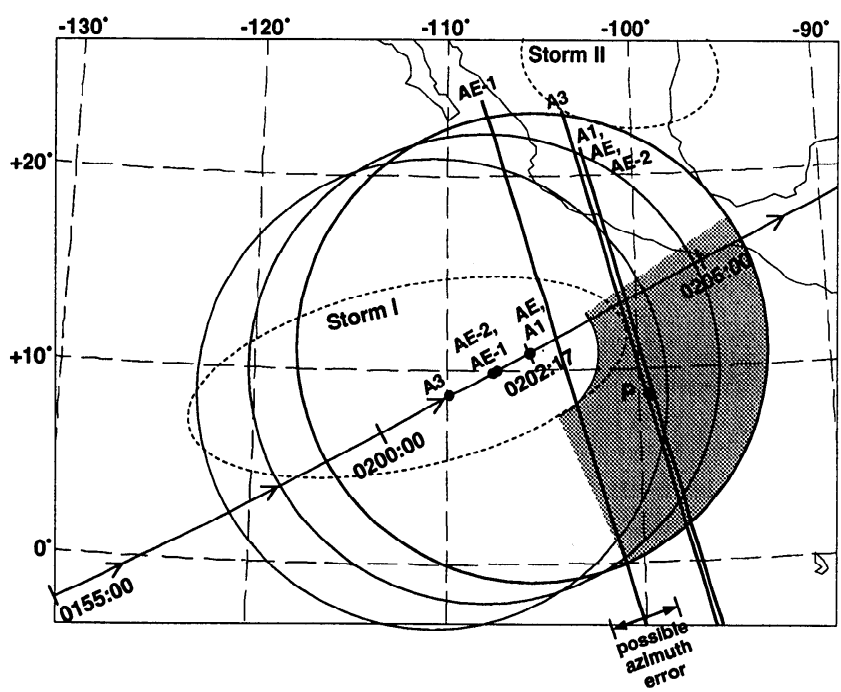

Figure 4. The encounter of CGRO with the thunderstorm center on 20 May 1993 (Case A). The solid circles on the CGRO track indicate the time of occurrence of indicated sferics, while the arrival bearings of these sferics are indicated as lines emerging from Palmer (see Figure 1). The horizon circles of CGRO, $\sim 2500 \mathrm{~km}$ in diameter, at the time of occurrence of the sferics are also indicated. The shaded region and the dotted ovals are the same as those shown in Figure 1.

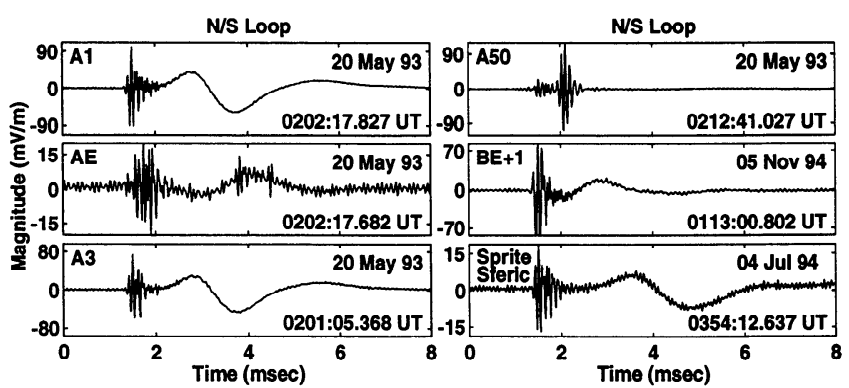

Figure 5. The waveforms of selected sferics observed at Palmer on 20 May 1993 (Case A) and on 5 November 1994 (Case B). The bottom right panel shows a sferic observed at Palmer on 4 July 1994, launched by an intense positive CG lightning discharge which occurred in the midwestern United States, and which was associated with a sprite [Sentman et al., 1995].

could not detect any gamma-ray burst associated with the 'most intense' sferic A1, occurring $145 \mathrm{~ms}$ later.

The waveforms of the 'event' sferic AE and sferics A1 and A3 (Figure 5) exhibit a so-called 'slow tail', consisting of an ELF asymmetric bipolar pulse, following the initial oscillating VLF portion [Hepburn, 1957; Sukhorukov 1992, and references therein]. The slow tail is a manifestation of the rclatively small attenuation for the zeroth-order waveguide mode, and theoretical calculations show that it is excited at significant levels by source lightning discharges with a slowly varying and lingering continuing-current component [Wait, 1960]. Therefore, the lightning discharge which generated the sferic $\mathrm{AE}$ may have had a continuing-current component contributing to the triggering of Burst 2348. Some other intense sferics from the same storm also had slow tails, and may have led to other gamma-ray bursts. Many other sferics with high peak intensity but with no detectable slow tail (e.g., sferic A50 in Figure 5) were observed with arrival bearings consistent with storm I in Figure 3. Note that the time-average intensity measure used here is well suited to the assessment of the slow tail intensity; therefore most of the 80-90 sferics more intense than AE (Figure 3 bottom panel) are likely to have had slow tails.

The slow tail of sferic AE may also be evidence of a possible connection between gamma-ray bursts and sprites. Sferic waveforms of positive CGs associated with sprites ex-

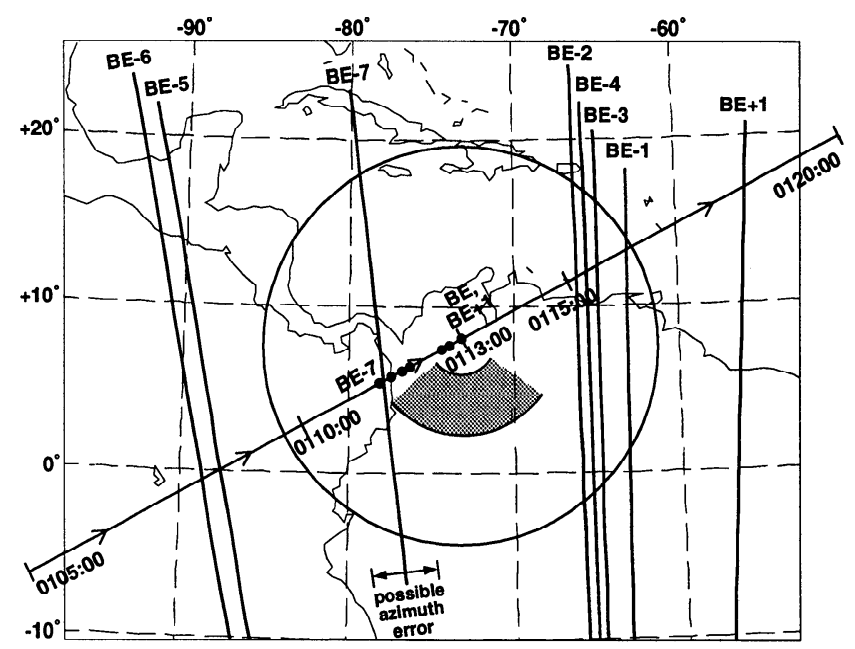

Figure 6. The encounter of CGRO with the thunderstorm activity on 5 November 1994. The format is identical to that of Figure 4. 
hibit unusually intense slow-tail components [Reising et al., 1995]. An example is shown in Figure 5; the 133-kA positive CG lighting which produced this sferic was associated with sprites (Figure 1 of Sentman et al. [1995]).

\section{Case B: Gamma-Ray Burst 3274}

On 5 November 1994 ELF/VLF data were recorded at Stanford and at Palmer (Figure 1). The relatively noisy Stanford data was not useful for measurements at low frequencies $(<5 \mathrm{kHz})$, and were used only on a statistical basis. Both sferics data and infrared cloud-top image data indicate a distributed set of storms at this time, which were either more active or closer in distance to Palmer than the storm near the CGRO footprint. Many sferics observed at Palmer near the time of Burst 3274 originated in other storms.

The occurrence time and arrival azimuth of some sferics more intense than $\mathrm{AE}$ are illustrated in Figure 6, including one (marked BE+1 and also shown in Figure 5) which occurred $\sim 60 \mathrm{~ms}$ after Burst 3274, accounting for travel times as in Case A. A sferic (BE) too weak for azimuth determination did occur within $\pm 1 \mathrm{~ms}$ of Burst 3274 . However, the rate of occurrence of such weak sferics was $\sim 20$ per second. The references to various sferics in Figure 6 as BE-2, BE-1, etc. are based on their occurrence time with respect to $\mathrm{BE}$.

If the production of gamma-ray bursts preferentially occurs in the identified source region of Burst 3274 (shaded region in Figure 6), due for example to particular thundercloud charge distributions, the fact that BATSE did not trigger on most of these earlier sferics (BE-7, -6, .., -1) is consistent with their arrival bearings, placing them outside this source region. The arrival azimuth of BE-7 is closer to the source region; however, even if $\mathrm{BE}-7$ led to gamma ray production, the lightning discharge could have been north or south of the region or the satellite may have been outside the gamma-ray 'beam'. It is possible that the gammaray burst was produced prior to a lightning discharge (e.g., the one which launched $\mathrm{BE}+1 \sim 60 \mathrm{~ms}$ later); another energetic upper atmospheric phenomenon, the so-called Blue Jets, is believed to occur without associated lightning discharges [Wescott et al., 1995; Pasko et al., 1996].

\section{Summary and Discussion}

We have presented evidence, in two different cases, of the association of terrestrial gamma-ray bursts with electrically active thunderstorms. Both of the thunderstorms produced many intense, positive CG discharges, one of which, observed on 20 May 1993, was clearly associated with Burst 2348 , providing the first direct evidence that at least some of the terrestrial gamma-ray bursts are associated with lightning. The occurrence of this sferic $1.4 \pm 1 \mathrm{~ms}$ earlier than the peak of Burst 2348 is consistent with the process of runaway acceleration of energetic electrons by intense quasielectrostatic fields which immediately follow lightning discharges [Gurevich et al., 1992; Bell et al., 1995].

Many of the positive CG lightning discharges surrounding the gamma-ray events exhibited intense slow tails, consistent with continuing currents that follow the initial impulsive charge transfers in the corresponding lightning discharges. The slow-tail waveforms of these sferics were similar to those of sferics associated with sprites. This connection provides the first evidence that sprites and terrestrial gamma-ray bursts may be different manifestations of the same physical process, most likely involving the runaway acceleration of energetic electrons [Bell et al., 1995].

Burst 3274 was not accompanied by a strong CG lightning discharge, since the sferic from any significant discharge would have been detected at Palmer. This experimental fact may indicate that terrestrial gamma-ray bursts may occur prior to lightning discharges, consistent with the fact that the runaway breakdown thresholds can be exceeded during the thundercloud charge accumulation phase, as may be the case for Blue Jets [Pasko et al., 1996].
Acknowledgments. The Stanford University component of this research was supported under NSF grant OPP9318596. S. Reising is supported by NASA Training Grant NGT-30281. The authors thank the MSFC DAAC for providing access to selected periods of NLDN lightning data.

\section{References}

Bell, T. F., V. P. Pasko, and U. S. Inan, Runaway electrons as a source of Red Sprites in the mesosphere, Geophys. Res. Lett., 22, 2127, 1995.

Boccippio, D. J., E. R. Williams, S. J. Heckman, W. A. Lyons, I. Baker, and R. Boldi, Sprites, ELF transients and positive ground strokes, Science, 269, 1088, 1995.

Boeck, W. L., O. H. Vaughan Jr., R. Blakeslee, B. Vonnegut, M. Brook and J. McKune, Observations of lightning in the stratosphere, J. Geophys. Res., 100, 1465-1475, 1995.

Brook, M., M. Nakano, P. Krehbiel, and T. Takeuti, The electrical structure of the Hokuriku winter thunderstorms, J. Geophys. Res., 87, 1207, 1982.

Budden, K. G., Radio Waves in the Ionosphere, Cambridge University Press, Cambridge, 1961.

Burgess, W. C., Lightning-Induced Coupling of the Radiation Belts to Geomagnetically Conjugate Ionospheric Regions, Ph.D. Thesis, Stanford University Department of Electrical Engineering, March, 1993.

Davies, K., Ionospheric Radio, Peregrinus, London, 1990.

Fishman, G. J., P. N. Bhat, R. Mallozzi, J. M. Horack, T. Koshut, C. Kouveliotou. G. N. Pendleton, C. A. Meegan, R. B. Wilson, W. S. Paciesas, S. J. Goodman, and H. J. Christian, Discovery of intense gamma-ray flashes of atmospheric origin, Science, 264, 1313, 1994.

Gurevich, A. V., G. M. Milikh, and R. A. Roussel-Dupre, Runaway electron mechanism of air breakdown and preconditioning during a thunderstorm, Phys. Lett. A, 165, 463, 1992.

Hepburn, F., Atmospheric waveforms with very lowfrequency components below $1 \mathrm{kc} / \mathrm{s}$ known as slow tails, J. Atm. Terr. Phys., 10, 266, 1957.

Lyons, W. A., Characteristics of luminous structures in the stratosphere above thunderstorms as imaged by low-light video, Geophys. Res. Lett., 21, 875, 1994.

Pasko, V. P., U. S. Inan, and T. F. Bell, Blue Jets Produced by Quasi-electrostatic Pre-discharge Thundercloud Fields, Geophys. Res. Lett., 23, 301-304, 1996.

Reising, S. C., U. S. Inan, and T. F. Bell, ELF/VLF radio atmospheric signatures of lightning flashes associated with sprites, EOS, 76, F105, A32C-8, 1995.

Sentman, D. D., E. M. Wescott, D. L. Osborne, D. L. Hampton, M. J. Heavner, Preliminary results from the Sprites 94 campaign: Red Sprites, Geophys. Res. Lett., 22, 1205, 1995.

Sukhorukov, A. I., On the excitation of the Earth-ionosphere waveguide by pulsed ELF sources, J. Atm. Terr. Phys., 54, 1337, 1992.

Wait, J. R., On the theory of the slow tail portion of atmospheric waveforms, J. Geophys. Res., 65, 1939, 1960.

Wescott, E. M., D. Sentman, D. Osborne, D. Hampton, and M. Heavner, Preliminary results from the Sprites94 aircraft campaign: 2. Blue jets, Geophys. Res. Lett., 22, 1209, 1995.

Westerlund, S., and F. H. Reder, VLF propagation at auroral latitudes, J. Atmos. Terr. Phys., 35, 1453, 1973.

U. S. Inan, S. C. Reising, STAR Laboratory, Stanford University, Stanford, CA 94305.

G. J. Fishman, J. M. Horack, NASA Marshall Space

Flight Center, Huntsville, AL 35812

(received November 15, 1995;

revised January 26, 1996; accepted February 16, 1996.) 